either by passing along these communicating vessels into the veins or else had passed into the veins by means of the direct continuity which Frohmann pointed out exists between them and the lymphatic vessels in the substance of the lymphatic gland itself.

In conclusion, then, I would urge the following considerations. 1. The azygos veins normally receive a great many lymphatic vessels. 2. Some of the smaller arteries in the thoracic region open directly into lymphatic vessels; some of the smaller veins open directly into the large lymphatic trunks; and these two factors help to quicken the movements of the lymph. 3. Direct communications are found to exist between arteries, lymphatic vessels, and veins. 4. The communications between veins and lymphatic vessels have been observed to take place in a great many regions in the body. 5. Owing to the presence of these communications the cells of a malignant growth can pass either from the lymphatics into the veins or vice versâ, and hence not only in the sarcomata but also in the carcinomata the veins, as well as the lymphatics, should always be regarded as channels along which the cells may at any moment be conveyed to distant parts of the body.

Wimpole-street, W.

\section{A CONTRIBUTION TO THE SURGERY OF THE KIDNEY.}

BY LEONARD W. BICKLE, F.R.C.S. EDIN., HONORARY SURGEON TO THE ADELAIDE HOSPITAL, SOUTH AUSTRALIA.

THE interest in Case 1 is of a twofold character. First. as another instance of the toleration of the pregnant uterus to abdominal section; and secondly, the smoothness of the case for the first week and then the febrile disturbance due to the recurrence of a dermatitis to which the patient was subject. The dermatitis in this attack was evidently due to the altered excretory conditions, as dermatitis and temperature alike fell when the urine from the remaining kidney reached a normal amount.

CASE 1. Nephrectomy during the third month of pregnanoy : recovery; subsequent normal delivery of a healthy infant at term. -The patient, a married woman, aged 29 years, the mother of four children, was admitted into Adelaide Hospital on March 7th, 1898, complaining of pain and swelling in the left side of two years' duration, which commenced with aching pain in the left side and the lower part of the back. A lump was first noticed about three months previously; the pain had increased much and was of a throbbing, burning character, but was not present every day. At times she passed a very large quantity of urine and then the lump or swelling got larger (?). The patient's father had died in hospital from "swollen knee" and her mother had died from "dropsy" after confinement. The patient had been married 11 years and had had four children. She had had one miscarriage two and a half years previously at about the sixth week. She had lost flesh of late. Her appetite was fairly good but she was unable to take food. Resonance and fremitus were normal. The breath-sounds were harsh and dry. The heart was normal and the arteries were healthy. The skin of the abdomen was flaccid, the lineæ albicantes were well-marked. On the left side a tumour which varied in size was to be felt. The patient had dragging pains when she tried to lie on the right side, but none when lying on the left side. The tumour was not to be differentiated from the left lobe of the liver. It was situated under the left costal arch, and though it was not moveable yet it came down with respiration. It measured about four and a half inches vertically and four inches transversely, it was not painful to touch, and was apparently cystic in character. The urine was of specific gravity 1020 ; it was clear, acid, and contained no sugar or albumin. The skin was very harsh and dry and was usually so, especially in winter. On March 14th the patient complained of much pain. On the 15th the urine was turbid and contained a small amount of pus and albumin. The urine had been measured daily so far, but had not varied much in amount. On the 17th a consultation was held; further observation was advised before operating. On the 27 th the tumour had increased in size and could be pushed into the loin; the patient's distress was greater. On the 29th, in view of the increasing size of the tumour and pain and the probability of the patient being pregnant, in further consultation a laparotomy was agreed upon and carried out forthwith. Chloroform was given by Dr. Kinınont. I started my incision from the costal arch at the linea semilunaris and continued it somewhat down and out for two and a half inches. On the abdomen being opened the cyst was found to be retroperitoneal. The incision was extended about one inch. The posterior layer of the peritoneum was cut through and the cyst was exposed. The cyst was tapped and a small amount of clear fluid with a faint urinous smell was drawn off. Whilst this was being tested the cyst suddenly ruptured. The fact that the cyst contained no mother or daughter cyst negatived a possible origin-viz., hydatid of the kidney. The thin walls of the cyst and the ready rupturing showed what would have happened later if the tumour had been left and the pregnancy had progressed. Having thos a hydronephrosis to deal with it was decided to remove the cyst and kidney rather than to leave a permanent urinary fistula. Accordingly the kidney was brought out and the pedicle was transfixed with a blunt needle and tied with a Staffordshire knot. The vessels and the ureter were re-tied on the face of the stump. No other vessels required tying during the whole operation. The abdomen was then flushed out with woric solution and the wound was closed with silkworm-gut sutures, a glass drainage-tube with a rubber drain being left in the lower part. The upper part of the wound was sealed with Whitehead's paint. The temperature after the operation was $96.8^{\circ} \mathrm{F}$. The afternoon temperature of reaction was $101^{\circ}$. There was no sickness for over 12 hours. A small amount of fluid was drawn off." On the 30th sickness and flatulence were a little troublesome and the temperature was $99.2^{\circ}$. The drainage-tube was removed and the stitch which had been left loose was tied. Three grains of subchloride of mercury were given and one ounce of haustus albus in the morning. The urine measured $8+6$ ounces. On the 31 st there was less sickness. The urine measured $8+9$ ounces= 17 ounces. On April 4th the patient's condition was good, all going well. The wound when dressed was found to be quite healed. On the 7 th the patient was not quite so well, complaining of pain in the left side; the temperature was $100^{\circ}$. On the 8th her general condition was about the same; there was some exudation about the stump. On the 10th she was better; ber skin was harsh and dry, and there was some dermatitis. On the 12th she had pains in nearly all of her joints and the dermatitis was very troublesome, preventing sleep. The temperature was $98.4^{\circ}$ in the morning and 100.4 in the evening. Sodium salicylate and sodium bicarbonate were given. On the 16 th the temperature was $984^{\circ}$ in the morning and $103^{\circ}$ in the evening. On the 18th the temperature was $99^{\circ}$ in the morning and $102.4^{\circ}$ in the evening; there was much irritation; the urine measured 21 ounces. The patient was sleepless. It was probable that the whole irritation and trouble were due to want of compensation by the right kidney. One-twentieth of a grain of pilocarpine was given every four hours. On the 19th the temperature was $98^{\circ}$ in the morning and $100.6^{\circ}$ in the evening. On the 20th the urine measured 43 ounces; the dermatitis was almost gone. The cicatrix was firm and sound. The temperature was $984^{\circ}$ in the morning and $99.4^{\circ}$ in the evening. The uterine enlargement steadily increased. There was no further trouble.

In due course the patient was delivered of a healthy child, the labour being normal in every way. She came to see $m$ some weeks later to show her child who was the picture of health. There was no vestige of ventral hernia. In August, 1899, I heard that the patient was quite well.

CASE 2. Nephro-lithotomy.-The patient was a man, 56 years of age, who first consulted me in September, 1891 complaining of pain in his left side of over 12 years dura tion. In the earliest onset once or twice he had passed blcod in his urine, but none since. The pain was aggravated by exertion and at times it was severe. He also complained of localised aweating. This was curiously marked. The unde vest would be quite wet for an inch or two in width round the zone of this pain which was that of the left renal region. The sweating was a great source of discomfort. I have noticed the same localised sweating since then in kidney cases. The urine was clear and pale, giving just a faint ring of albumin with cold nitric acid. Microscopically a fer blood corpuscles, leucocytes, and crystals of oxalate of lime were seen. The diagnosis arrived 
at was stone of the oxalate variety in the left kidney. The patient was very loth to accept the diagnosis as he had consulted several other medical men who had not suggested it. He was a very bad subject for surgical interference, and as he refused to hear of it a temporising policy was pursued. Belladonna locally and lithia citrate internally with an occasional opiate at night until the end of the year rendered life tolerable during 1892 and 1893 . He always had the dragging pain, but, as he expressed himself, it was bearable; occasionally he came to see me. In October, 1894, he had profuse hrmaturia so free that the question of cutting down on to the kidney was discussed. By rest and astringents it abated. The hwmaturia clinched the diagnosis. After this he was occasionally worse and better, still preferring to temporise, although told that an operation was the only course. In August, 1896, he came saying that life was unendurable. He was directed to go home and to bed, and two days Jater, with the kind assistance of Mr. J.C. Weld and Mr. C. D. G. Morier, I cut down on the kidney by the usual lumbar incision. No stone could be felt by the finger, but after the systematic use of the searcher a stone was struck, the kidney was incised, and with some difficulty the large stone here figured was removed. The hæmorrhage was very profuse, so the wound was closely packed and the patient was made comfortable. A few days after the operation a small nucleus of oxalate was passed. Convalescence was a little retarded by some infiltration of urine into the tissue of the back, necessitating free incisions. From the tenth to the seventeenth day after the operation his mental condition was very serious (an afebrile delirium). but after the seventeenth day he recovered rapidly. On the twenty-seventh day urine ceased to come from the wound; he har then been up in a chair for some few days.

His recovery has been complete and from being a man prematurely aged, of slow, bent gait, and generally depressed condition he is now (three years after the operation) a fairly brisk, cheerful man to whom life has ceased to be a burden.

The accompanying illustrations give a good idea of the

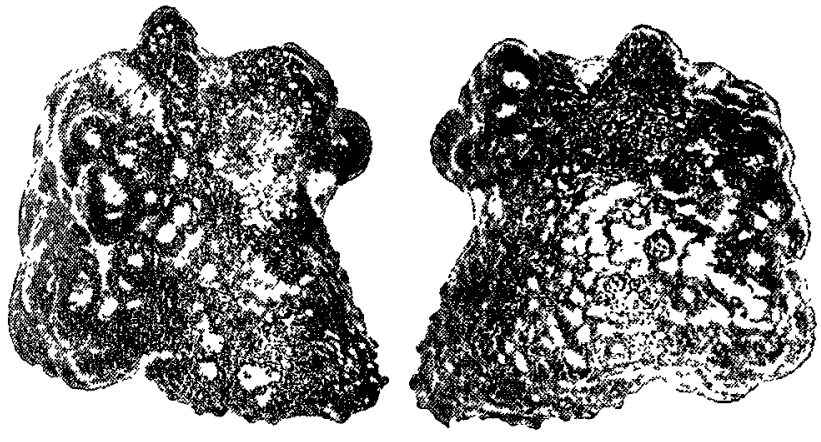

Two aspects of the stone.

stone and of its actaal size. It was clearly an oxalate with some deposit of phosphates; it weighed rather over 240 grains. It is not a little remarkable that so large a stone should only have produced one serious attack of bæmaturia, that attack occurring two years before the removal.

Adelaide.

\section{HALLUX VALGUS AND HALLUX VARUS.}

BY J. JACKSON CLARKE, M.B. LOND., F.J.C.S. ENG., SURGEON TO OUT-PATIENTS AT THE NORTH-WLS'L LONDON AND CITY ORTHOP FDIC HOSPITALS

Definition of terms.--The fact that in Latin the terms "valgus" and "varus" were used inversely to the manner in which we use them need hardly be made the subject of discussion, since their misuse has become so well established that their meaning is never in doubt. When it is desired to express accurately the nature of the deformity some careful consideration of the meaning of words is desirable. In different languages the terms "abduction" and "adduction" as applied to the great toe are used in opposite ways: thus Hoffa defines hallux valgus as an "Abductionstellung" of the great toe. Redard terms it "outward deviation" of the great toe, but uses the terms "adduction" and "abduction" in

1 Intrnduction to a discussion at the meeting of the British Orthopædic Society held on Feb. 17th; 1500. the same sense as Hoffa-that is, conversely to their employment by English anatomists. Perhaps it will be simpler to follow the continental fashion in this matter and make the meaning of the term "abduction" clear by adding the qualifying phrase "from the median sagittal plane of the body." There is in hallux valgus something more than this and I should be inclined to suggest as the complete definition the following:- Hallux valgus is a deformity in which the great toe, when the foot is at rest, assumes a position of abduction from the mesial sagittal plane of the body and at the same time is, to a greater or less extent, subluxated outwards, it being understood that normally the great toe lies in the same plane as the first metatarsal bone. Hallux varus is the condition converse to ballux valgus.

Anatomy. - The internal lateral ligament is elongated, sometimes thicker, sometimes thinner, than normal. With the outward displacement of the base of the first phalanx there is a corresponding outward displacement of the sesamoid bones and the flexor, extensor, and other tendons. The cartilage of the inner part of the head of the first metatarsal bone tends to undergo fibrous metaplasia, and an adventitious bursa to form between the internal lateral ligament and the skin over the exposed incer part of the head of the metatarsal bone. In persons suffering from rheumatoid arthritis or gout the anatomical changes of these conditions, separately or combined, are present. In rheumatoid arthritis there is, I believe, constantly a groove denuded of cartilage and lined by rarified bone; the groove is caused by the pressure of the inner margin of the base of the first phalanx. Extensive villous overgrowth of the synovial membrane may be present in the same class of case, and I have also observed both in operating and in making post-mortem dissections that in rheumatoid cases the internal lateral ligament is usually thin and often allows the adventitious bursa to communicate with the joint cavity. The changes in the heads of the metatarsal bones as seen in a case which I have previously reported to the British Orthopæedic Society are shown in Fig. 1.

Fig. 1.
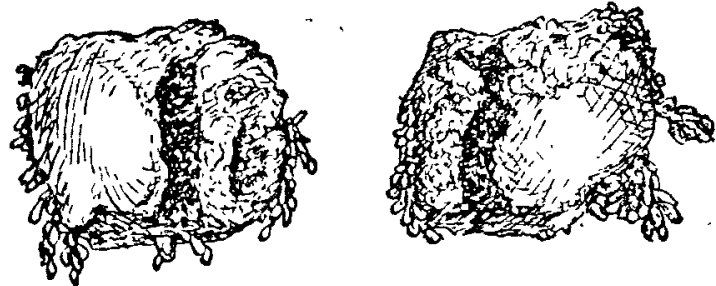

The anterior surfaces of the heads of the metatarsal bones removed for hallux valgus in a case of rheumatoid arthritis.

Causation.-Congenital hallux valgus, though far less common than acquired, is met with from time to time. I can recall three instances that have come to my notice in the past three years. One was that of an infant a

FIG. 2.
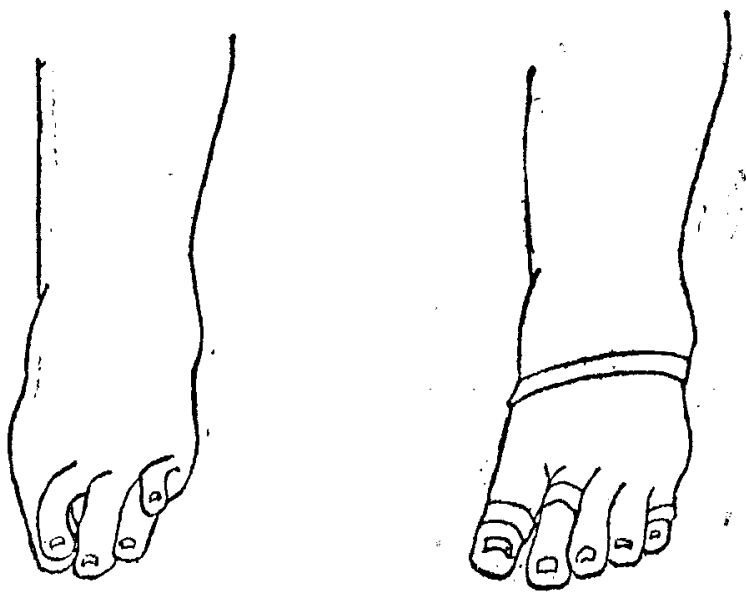

The left foot of an infant with congenital hallux valgus, \&c. and (to the right) the same fout with the deformitie corrected by strips of arlhesive plaster.

few days old. In this case there were about 40 degrees of hallux valgus, the second toe was displaced upwards above the great toe, and the little toe was displaced inwards upon the dorsum of the foot, as shown in Fig. 2. The toes were 